\title{
Urban Planning in Africa: Which Alternative for Poor Cities? The Case of Koudougou in Burkina Faso
}

\author{
Jean-Claude Bolay \\ CODEV (Center for Cooperation and Development) \& LaSUR (Urban Sociology Laboratory), EPFL \\ (Swiss Federal Institute of Technology, Lausanne), Lausanne, Switzerland \\ Email: jean-claude.bolay@epfl.ch
}

Received 30 November 2015; accepted 21 December 2015; published 24 December 2015

Copyright () 2015 by author and Scientific Research Publishing Inc.

This work is licensed under the Creative Commons Attribution International License (CC BY). http://creativecommons.org/licenses/by/4.0/

(c) (1) Open Access

\begin{abstract}
The efforts made to plan cities in emerging and developing countries are confronted to multiple issues, especially in small and middle sized cities which can be considered as poor through several criteria: socio-economic level of majority of population; low levels of public investments, weak quality of local administration, and large dependence of external donors. Following several authors, one of the main reason is that philosophy and methods of urban planning applied to these specific contexts are directly reproduced from a Western tradition which doesn't correspond to the local and national context in terms of needs, priorities and organization of the financial resources. The case of Koudougou, a medium sized city in one of the poorest countries in the world, Burkina Faso, will give the opportunity to understand concretely how these deficiencies are translated in an urban context, and foresee, more globally, alternative models of urban planning better adapted to poor cities, whose number of inhabitants is growing steadily.
\end{abstract}

\section{Keywords}

Poor Cities, Urban Planning, Urban Development, Alternative Models, Developing Countries, Africa, Burkina Faso, Koudougou

\section{Planning and Urban Theories, Questions and Links}

Urban planning is both a technique and a method of the observation and analysis of spatial, material and human reality. It is also a vision of what the city will be in the near and distant future. It is known above all by its projective and operational actions. But urban planning requires theoretical foundations, i.e., a body of knowledge 
and ideas that enable the understanding of a reality, and that give it direction, in the present, in its historical foundations, and in projections made in the future. It would be dangerous to separate these two dimensions of planning, one more reflective and the other more applied, even if in reality, these separate but complementary conceptual dimensions are only rarely integrated into the discourse and/or practice of urban stakeholders, whether they are urban professionals or researchers. Which is the case whether one is in Africa or elsewhere in the world.

There is a discourse, or better said, discourses about the city; and these reflections evolve, diversify, or even conflict, in the same manner that reality changes, going from the city to the urban, according to Françoise Choay (1999). These spatial and social transformations take place in environments that, in turn, are both in the normativity of a globalized urbanization, following similar models, and yet in the complex ambiguity of a gigantic heterogeneity (Paquot et al., 2000), borne of distinct local and national histories, of indigenous cultures and social practices, and of natural, climatic, geographic environments, specific to their locations and sites. This complexity must be taken into account in our discourse on the city and urbanization (Ascher, 2000). In the words of Harvey (2012), common points, cities, are the place where people of all kinds and all classes gather, willingly or unwillingly, to produce a constantly changing, common life. For Castells (1969), referring to the work of researchers from the School of Chicago, 1920, the contemporary city can theoretically be conceived as a "specific cultural system, producer of norms and values characteristic of modern societies, a space shaped by the transformations of the socio-economic structure; an ecological self-balancing organism to meet the new needs created in its interior or induced from the outside”. This ecological and social diversity, from the 20s, shows that the city is more than urban planning and architecture. And that understanding it involves fieldwork, an anthropology that enables capturing the processes that generate the urban changes (Judd, 2011). These perspectives, from this point of view, allow us to keep some generic elements, which also apply to the South: The city is first and foremost a social system, characteristic of modernity made of societal interactions and techniques. And the city is changing under the influence of social, economic and technological transformations, forming an environment that is both natural and constructed, a form of urban ecology, confronted by endogenous and exogenous conflicts of interest. Its socio-spatial dimensions are polymorphic, variable and dynamic (Brenner \& Schmid, 2014), making it impossible to give it an unambiguous definition, accepted by all. Even in its demographic evolution, the definition of the city, by its number of inhabitants, varies from one country to another. It is therefore, beyond spatial extension and demographic growth, by societal criteria (social, economic, cultural, environmental) that we will seek to understand the contemporary city, and more broadly, the urban phenomenon. Neil Brenner (2009) highlights the deep transformations of contemporary society in recent decades. As already shown by Lefebvre in 1970, urbanism is a phenomenon that continues to expand in the already heavily industrialized regions of the world, by a diversification of land use, infrastructure put into place, from the reconfiguration of ruralurban interfaces and in the modes of investment and governance. What is new, and is our primary interest, is that this urbanization process now affects the entire planet, "racing" at a speed never before experienced in countries urbanized on a small scale, in which the escalation and expansion of the process generalizes and modifies, at different scales, the territory as well as social relations. This is especially the case in Africa, still the least urbanized continent in the world.

Three observations of Lefebvre (1970) still challenge us today. The concept of urban centrality, which is not exclusively spatial, by the concentration of people and infrastructure, but which is first and foremost political and economic, in a production mode of a capitalist world, extending across the globe (Bolay, 2006). Then the identification of new rarities that we must learn to manage: space, land, water, time, etc., that compete in complicating the urban reality. And the third element, the human, environmental and technological complexity, which makes urbanization a global reality for which the fragmentary sciences, in the words of Lefebvre-thus the different disciplines concerned with the city — can only give a fragmentary analysis of this reality. As stated in Scott and Storper (2015), the debate is endless because, based on a multi-dimensional subject and on continuous transformation, different currents of thought confront each other, some to deny the prevalence of an urban singularity, others to decipher the different characters: global city, neo-liberal city, creative city, ordinary city, and post-modern city.

These semantic distinctions deserve to be taken into account. Certain general trends must nevertheless be remembered; as this is a global phenomenon that now massively impacts emerging and developing countries. It is first the synergy that exists between economic development and urban development, cities being, at the global level, high-tech hubs, driving forces of contemporary economics (OECD, 2006). Although these trends may be 
more diffused in highly industrialized countries with dense and diverse networks, they remain significant in many developing countries, with a city, usually the capital, sometimes accompanied by two or three large agglomerations, which polarize all the elements of modern technology and economic attractiveness. Infrastructure density and the sophistication of services are all assets, regardless of the country or regional context, which reinforce the centrality of the city, its dynamism and its social interactions. And new communication technologies have not substituted a connective virtuality to this physical and human reality; they reinforce these ties and expand them, sociologically and spatially. Cities are also concentrations of power, initially political sincedepending on the city-national, regional and/or local authorities are found there, but also and above all economic, holding the main private and political actors who invest, who produce and manage, both materially and financially. All this makes the cities fantastic decision centers, whose actions will impact well beyond their own borders: public administrations, banks, markets, shopping centers, small and large companies, political parties, churches, and lobbies.

Before seeking how planning, as it is thought and practiced, is tailored to cities in the South, we must recognize that we will find, in all latitudes a few symbolic dimensions that will characterize urbanization: spatial and economic polarity; the centrality of political and economic powers; the concentration of individuals, capital, goods and activities; and the dynamics of proximity, of gathering and of interaction. Cities per se are systems—a network of elements that are interdependent (as much technologically, institutionally and sociologically) —and together form a system of systems, according to the sectors concerned (Wyly, 2012) and have now become the fabric from which contemporary societies are configured.

These urban characteristics are present everywhere, in the history of cities as in their current geographic diversity. But our wish is above all to be aware of the questions arising in the South regarding the forms of land planning produced by the application of urban planning methods and instruments, essentially exogenous to their problems, and to their contexts.

\section{Urban Planning in the South, or the False Encounter}

Fraud or accumulated errors. The first observation that can be made by anyone reluctant to criticize for the sake of criticizing, but willing to open their eyes to reality, is twofold: First, it appears that the results of urban planning, as applied in developing countries, whether in Africa or elsewhere, only partially address the real problems facing urban populations. It is partial on the territorial level, covering only certain parts of the city, generally abandoning precarious housing neighborhoods, areas poorly regulated by law, and peripheries. It is biased on the socio-economic level, focusing primarily on the areas invested in by the privileged social actors of urban society, on the basis of their financial status, their relations to power, or even their community or ethnicity. Second, it appears that there is a caesura between planners, urban policy makers and residents. And this is largely because the fundamentals of planning were built in the North and then transferred to the South, without having been redesigned on a clear basis, but simply adapted to other physical, political and financial constraints.

Devas et al. (2001) concluded from a comparative study conducted in ten cities of the South that in these cases overall, the standard chosen in infrastructure, equipment and buildings were totally unsuitable to the conditions of the poor, but that they formed a perfectly workable system of regulation by individuals with power, whether economic and/or political. And this is explained, according to Edensor \& Jayne, in their introduction to the book "Urban theory beyond the West" (2012), by the fact that the methodological and technical discussions are dominated by Europe and North America. In this perspective, cities of the South are almost always considered less "modern" than Western cities (without really clarifying why cities in the South are less modern, but indirectly related to apparent signs of technological wealth and communicational and technological visibility), concentrations of problematic situations, perceived negatively in comparison to European or North American reference models. Yet cities in the South are gradually, and at an extremely rapid pace, inserted in the world of economic globalization, also serving as new communication tools. This economic and political integration of countries less marginalized than 20 - 30 years ago had the effect of commodifying even more the relationship between urban society and its territory, by investment priorities (public budgets facilitating the emergence or the strengthening of private operators), by the privatization of many collective services (water, energy, transportation, culture, public spaces, to name only the most obvious sectors), and by the globalization of participants.

For Watson (2009), demographic and territorial growth of cities in the South inevitably causes a concentration of poverty and social, economic, but also spatial inequalities in cities. Without urban planning, as it is practiced, 
being able to apprehend them with anticipation, or even to solve a multitude of intertwined problems, between on the one hand the local needs, of each family, of each community, of each neighborhood, and on the other hand the production by the specialists of planning based on the entire urban territory. Increasingly integrated into the world market's economic globalization, countries of the South and the cities that animate them are not only faced with a continued influx of population on under-equipped territory, they are also less and less able to offer these new urbanites and the younger generation job security. The city of the South is characterized by the growing informality of its economy, diversified in the form taken by these activities, but, at the same time, signs of individual and social integration into the urban fabric and a source of social tension between urban authorities, formal entrepreneurs and informal workers that are blended in using all the means that remain accessible to them (Bayat, 2004). Precarious living conditions, at different levels, are reflected by a continuous expansion of slums on the fringes of the models adapted by policy makers and planners, but central to urban issues, by the increasing number of people living there, by the key problems to be addressed. As expressed by Roy, the slums reflect both a territorial exclusion, through the lack of equipped spaces accessible to the poor, and the tensions arising from the occupation by the poor of land that sometimes becomes very attractive for the market development of the city (Roy, 2004). Which does not prevent, without any planning, the inhabitants of the slums to greatly contribute to the economic and social dynamics of the city: job creation, income generation, community organization, and social and political participation. Also according to Watson, the question is twofold, first the models that inspire these professional practices come from the North, based on totally different socio-spatial contexts; on the other hand, planning is primarily viewed as an implementation of future territorial interventions, in a purely technical posture, with little concern for local urban history, the actors involved, the interests at stake and, more generally, a societal vision taking into account all of the urban community, in its various components, especially the poor who, as is often the case in cities in Africa, represent the majority of citizens. As Roy stated (2005), there is no connection between the spatial and the social. One thinks territory, networks, development, equipment, but without interest in how people live. Informality is the only way for the poor to integrate, willingly or unwillingly, to the city; most often they are neither consulted nor involved in planning decisions. With the result being investments that are often poorly targeted and do not address the crucial questions that the majority of urban dwellers are facing. The question arises in terms of equipment choices to focus on, but also, and most often, in terms of conditions of accessibility, as costs are not adapted to the financial conditions of the most underprivileged segments of the population. These changes have resulted in increasingly marked urban land fragmentation, the gentrification of neighborhoods according to their level of equipment, and a socio-economic segmentation of the functions and uses of the city. The alternative, according to Yftachel (2006) would be to question five key dimensions of urban development: land-use and its allocation criteria; the policies put in place to fight against segregation; decision-making procedures, in a way that adapted forms of social participation fight against exclusion of the urban poor; the consideration of the socio-economic conditions of urban dwellers as a whole and particularly groups in the disadvantaged population; as well as the financial impact of urban transformations, especially in terms of increasing the value of land and property of rehabilitated neighborhoods.

Faced with this conflict of rationalities - on the one hand public power and private investors, primarily concerned with urban competition and profitability, and on the other the majority of citizens interested in their integration and access to urban services - urban planning should aim to be an instrument to fight against mass poverty in favor of a more inclusive and just city. And for this reason give priority attention to different facets of informality—employment, land, housing, core networks such as water and electricity —in a way that supports the efforts of the poor to access dignified conditions in urban life, rather than promoting the megaprojects that cause their marginalization and often their displacement to an even further periphery (Harrison, 2006).

The city — African, Asian or Latin American — must first be understood as part of a changing world, materially and technologically, but also, and above all, human. A significant number of variables must be included in the planning process, taking into account interactions between social, ecological, economic, political and administrative dimensions. Planning, as believed in the 60s, is no longer appropriate. It can no longer be designed in a linear and progressive perspective, insofar as it applies to rapidly changing territories, whose evolution is often misunderstood (Yftachel, 2006). It must, on the contrary, accept a certain level of uncertainties, which, to be understood and accepted, need to be integrated into the planning process itself, by a communication and collaboration effort between stakeholders (Woltjer, 2000).

Bearing in mind the specificities of the majority of cities in the South, the first variable to consider in appropriate planning in these contexts is the fight against urban poverty (UN-Habitat, 2008) in its different facets and 
consequences at various levels. Tannerfeldt \& Ljung (2006) emphasize that urban poverty is relative, considering the local context and the social and economic inequalities. Financial and economic criteria are not the only ways to characterize urban poverty. In addition, indicators based on health, education, environmental quality, violence and insecurity, represent a multitude of risks that these poor families must confront. Tacoli, McGranahan and Sattethwaite (2015) designate urban sectors where the poor are systematically marginalized: insecure tenure, poor quality housing and a lack of public provision for infrastructure. Which explains that, faced with these shortcomings, residents of precarious districts must cope alone to solve these basic needs.

Applicable to Africa, as elsewhere in the contemporary world, the proposed changes do not at all depend only on implemented planning methods. These changes do not generally operate with transparency and dialogue. Many aspects of the process remain opaque, inaccessible to many, even simply disregarded. They result from goals that, according to the actors involved, are divergent or even in conflict with each other. This should lead us to think of urban planning as a creative approach, innovative, ready to face the unexpected, and not as a routine approach doomed to failure (Grunau and Schönwandt, in de Roo \& Silva, 2010).

\section{African Cities, an Off-Plan Urban Development}

As Chenal (2013) said with humor, urban planning of cities in Africa is reminiscent of the video game SimCity. Everything seems possible. And the recipes for a "good city” are simplistic. The urban reality is less so: demographic growth and territorial expansion, poverty, environmental degradation, and informality of a significant portion of urban activities. All questions that, obviously, challenge urban planning, in its approach and its aims, and the participants who are in charge of managing the present and thinking the future of the African city.

According to UN-Habitat (2014) Africa's population was approaching a billion people in 2010, should reach two billion in 2040, and exceed three billion in 2070. This population increase will first and foremost be in the cities. Since the 1990s, globally, urbanization is the strongest in Africa. Although the annual rate of urban growth has gradually decreased over the decades, to $3.29 \%$ in the years $2000-2010$ in comparison to $4.16 \%$ in the 1980s, it remains very high. Currently 400 million citizens represent $40 \%$ of the African population. In 2050 , there should be 1.2 billion citizens, representing $58 \%$ of the continent's population. As we recently indicated (Bolay, 2011), this spatial and demographic expansion and its effects in terms of poverty and urban insecurity should be the foundation of urban planning in Africa. Many African cities have in common discontinuous territorial development, dispersed in the periphery and with low land occupancy, whose influence extends continuously further in the suburbs and farmland, thereby causing shifts. Which could put into question coherent regional development between the city and the countryside (Nunes Silva, 2015).

A second element of identification is due to imbalances in the urban network of many African countries, marked by macrocephaly of a metropolis, at the expense of all other cities. This is the case in Senegal, the Ivory Coast, Madagascar, Mauritania, Nigeria, and Kenya, to name a few, by which the question arises of what happens outside these, multimillionaire megacities in terms of inhabitants. How does the city (and life) get organized in small and medium-sized cities that do not have this same attractiveness to offer? Yet these intermediate cities also reproduce another feature of urban Africa, which is that of the territorial sprawl. Few cities appear concentrated, vertical, or densified. Their morphology is marked by blurred boundaries, a fragmentation of the territory, made of drafted subdivisions, of land occupied by buildings under construction. Technical and road networks are extremely expensive on any development of large areas that are being urbanized. These cities are also confronted by the informality of activities. According to an ILO study, cited by Benjamin \& Mbaye, the informal sector accounts for $72 \%$ of jobs in sub-Saharan Africa, of which $93 \%$ are newly created jobs, while the formal sector would employ 10\% of the workforce on the continent (Benjamin \& Mbaye, 2012). According to the ILO, wide variations are found from one country to another, going from $33 \%$ of non-agricultural employment in South Africa to $82 \%$ in Mali, most of this non-rural informal sector being made up of independent jobs with no security-craftsmen, shopkeepers, street vendors, etc. (ILO, 2014).

We must also remember the diversity of urban areas. Small and medium cities account for the greatest urban areas in Africa and receive most immigrants from rural areas. They are, with a lower level of population, cities whose demographic growth is the highest. 52\% of the urban population in Africa lives in cities of less than 200,000 inhabitants, in comparison to $42 \%$ for all developing countries (Kessides, 2006). It should also be noted that these small and medium cities - in surface area as well as number of inhabitants-are also intermediate cities (Bolay \& Rabinovich, 2004) as long as they have a central role with regard to nearby rural areas, meaning both 
the continuum between rural and urban (Montgomery et al., 2004) but also their distinctions as regional urban centers (Bolay et al., 2004) endowed with services and infrastructure that are not only urban and local, but regional (public administration, business, banks, hospitals, etc.). But, like small and medium cities in Europe or other industrialized regions (Knox \& Mayer, 2009), these agglomerations in Africa benefit less directly from the globalization of economic exchanges, and can sometimes suffer the consequences of a local market undermined by competitive imports. Their dynamic will be largely dependent on their physical and economic integration with national urban networks (particularly through the quality and density of the road network and in terms of public transportation, especially as centers for processing and transferring agricultural products).

Myers (2011) seeks, by comparing different African cities, a way out of Western models that shape the belief about the African city, by highlighting the diversity and specificities of urban development patterns on the continent. While being aware of the heavy colonial influence in its urban realization, but also neo-colonial in the minds of "city makers", he stressed that urban Africans develop their own forms and their own standards of building and managing the city, often forced to do so, taking into account their living conditions and the lack of government intervention. Many are poor, but the poor who act, who create their employment—often informal, their housing, and their neighborhood. And they do so-this self-construction of the city—while confronting other forces: the land market, the real estate industry, distributors of technical networks, not to mention the public authorities and their administrative arms. Although this logic appears conflictual, it is often the subject of negotiations. The regulations in place are known, even if they are diverted. And one knows that land ownership depends on modern, official law, but also on traditional authorities having power over customary land. These African specificities are conducive to arrangements between stakeholders, other than those that can be observed on other continents. These practices, formal and informal, that make the African city, are yet to be anchored in innovative modes of urban governance, based on the facts and actions taken by the residents. Indeed, if one refers to housing and informal economic activities, most of the urban poor in Africa consider, against public authorities, that their activities, undeclared or even illegal, are not only legitimate, but also normal and functional (Tranberg Hansen \& Vaa, 2004). Here we touch on an African specificity that makes the city not only a dichotomy between a postcolonial center and a recent informal settlement, or between self-construction in precarious housing neighborhoods and modern networks run by the city authority (roads, water, electricity, waste management), but also and above all a superimposition of references, as is the customary land right against the modern law inherited from the European colonies, with which each plays to implement development strategies, each one in its own way, each one in its environment (neighborhood development matched against master plans decided in high places, and rarely enforced).

Fortunately things are changing and insights are emerging across Africa to try to better ensure consistent urban theories, planning methods used to date, and actions to which they lead.

For Agboda \& Watson (2013), African cities are changing rapidly and many investments, notably in real estate and equipment, change the landscape. The problem, according to their study, is that these changes have no real impact on fundamental problems to solve in favor of sustainable urban development. The majority of these implementations are inadequate in terms of climate and infrastructure, and access is limited to the African and foreign elite. In general, these projections, designed at the level of the central government, were either inspired directly by planning standards carried over from the colonial period, or try to appear original and extravagant, but ignore the informal city, by either denying it or making it disappear. The formal city is becoming increasingly inaccessible to mere urbanites, and precarious settlements are stretching out to the periphery.

Faced with this trend, the Association of African Planning Schools was created in 2008 as a network of 43 institutions that train urban planners, which began an effort to reform planning education on the continent. According to its coordinator, one must first realize that urbanization in Africa "does not follow the 'conventional' patterns of industrialization and concomitant job creation in the North, where rapid urban growth was first experienced (Jaffe, 2011). Rapid urbanization in Africa is simply not matched by the job creation required to secure livelihoods, and public intervention is not keeping pace with the demand for shelter and land". Most urban master plans do not take into account the informality of urban life, either social, economic, property, or land-use. These dimensions of the life of the poor must be reinstated in the planning, in training curricula of future professionals as in their practice, once they are at the command posts. This, so that planning no longer serves as a control of inappropriate standards, but strives to bring order and harmony to the existing cities and better organize the future of cities, first taking into account those who live there and who bring them to life. 
As stated, personally, by Harrison, Todes and Watson (2008), in the introduction to their book "Planning and Transformation", taking stock of the post-apartheid experience in South Africa, "the purpose of planning is to contribute to the realization of socially just and sustainable cities and regions, although we recognize that there are different interpretations of what these concepts may mean. To this end we believe that both the process and products of planning are important and that they cannot be considered separately from each other." We concur with these remarks that give meaning to what future urban planning in Africa should be.

\section{Koudougou, a Poor Town in Africa}

To put flesh to these considerations, the history of Koudougou, Burkina Faso, will serve as an example.

With a little more than 100,000 inhabitants, Koudougou is located 100 kilometers west of Ouagadougou, connected by a wide paved road. It is the capital of the province of Boulkiemdé, prefecture of the department with the same name and capital of the Central West region. It is a major city, the country's third largest in population, following the national capital and Bobo Diolasso. The existence of Koudougou as an urban hub goes back to the late nineteenth century with the arrival of French settlers and the forced migration of rural populations to increase the number of its inhabitants (Hilgers, 2005).

First impressions, as shown in Figure 1, the spatial expansion and the very low constructive density. At the entrance of the town, for the moment there are only parcels apparently with very little cultivation, land with tentative buildings, small brick or adobe houses; everything is both in the present and emerging; the houses are inhabited but are being often extended, or of one level. And this, until the arrival of vital forces to the new neighborhood, kicked off with ostentation on the occasion of the Independence Day festival on 11 December 2012.

Koudougou, after leaving its suburbs, stands as a true open-air shopping center. The city offers all conceivable sales activities: fresh food, restaurants, cafes, workshops and stores where everything is sold, from mechanical parts to clothes imported from abroad, music that wafts from taverns. And individuals on bikes, on motorcycles, on foot, and more rarely in cars. Koudougou is a lively, vibrant town. And this, even though the size of the buildings remains modest, rounded-up buildings, glued to each other in the centrality of a vast territory. And

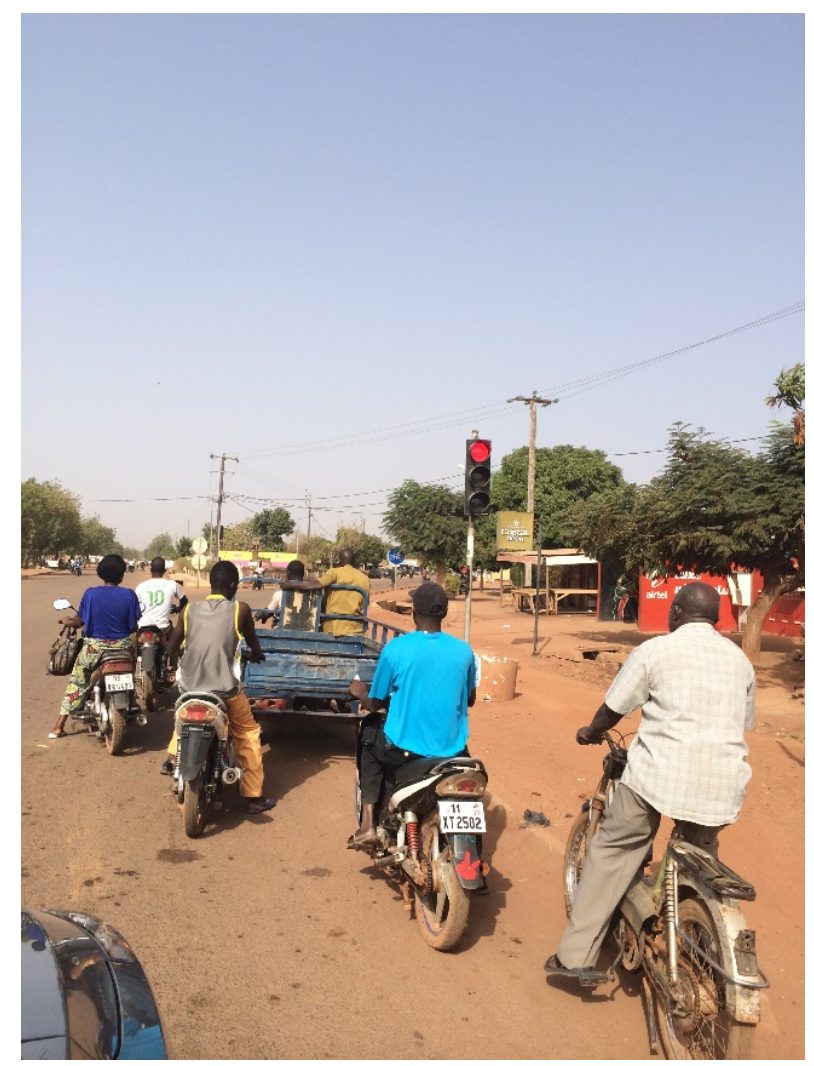

Figure 1. Unpaved street in the center of Koudougou (photo: J-C Bolay, 2014). 
everywhere the color of earth: the paths that escape from the main roads, the colors of the houses, everything is mixed from beige to brown, sometimes ocher. A rural town in which the peasant who comes to sell something in the market should feel at home. Moving through the center, one quickly finds that mixture of urbanity and rurality, plots still empty, houses nearing completion, billboards. A city that exists, but that is lived as a village, a huge town that nobody could suspect, in the light of other cities of its size in the world, that 100,000 people of all ages live there.

Ultimate impression of the newcomer: the city seems extraordinarily clean, the downtown streets are cleaned, the street stalls are neat, the two markets visited are orderly and cleaned, little garbage is lying around the margins of the crossroads.

Burkina Faso is a country of 274,200 km², divided in 13 regions and 45 provinces, as illustrated in the Figure 2. With a population of 18.3 million of inhabitants, Burkina Faso has $77.30 \%$ of the population living in rural areas and $22.70 \%$ in urban areas. Clearly, the Burkinabe population is predominantly rural. $46.4 \%$ of the urban population lives in Ouagadougou, the national capital. More broadly, $76.8 \%$ of the Burkinabe urban population is concentrated in the 10 most populated cities in Burkina Faso, with an average annual growth rate of the urban population of around 7.26\% between 1975 and 2006 (MHU, 2012). The Burkinabe urban population represented in 1975 only $10.8 \%$ of the national total, this percentage increased to $18.5 \%$ in 1990 and reached $24 \%$ in 2010 . If this trend continues, it could be between 37\% and 44\% in 2030 (UN-Habitat, 2007).

For evaluators from the World Bank, the contemporary urban development in Burkina Faso is divided into three periods: from 1960 to 1983, urban planning emerged in the light of colonial times, with two types of zoning, one for the poor indigenous, and the other, residential and equipped with roads, drainage and electricity, for Western expatriates and African officials. The revolution led by Sankara in 1983 had an urban impact; land was nationalized, and a public national land agency was created. A highly centralized national policy was conceived to regulate land and housing issues. This was the beginning of the creation of many housing developments and land grants. Since 1990, after the fall of the ruling regime, the new government began negotiations with the World Bank in order to create and strengthen technical departments responsible for urbanization in Ouagadougou as well as in Bobo-Diolasso, the two main cities in the country (World Bank, 2002).

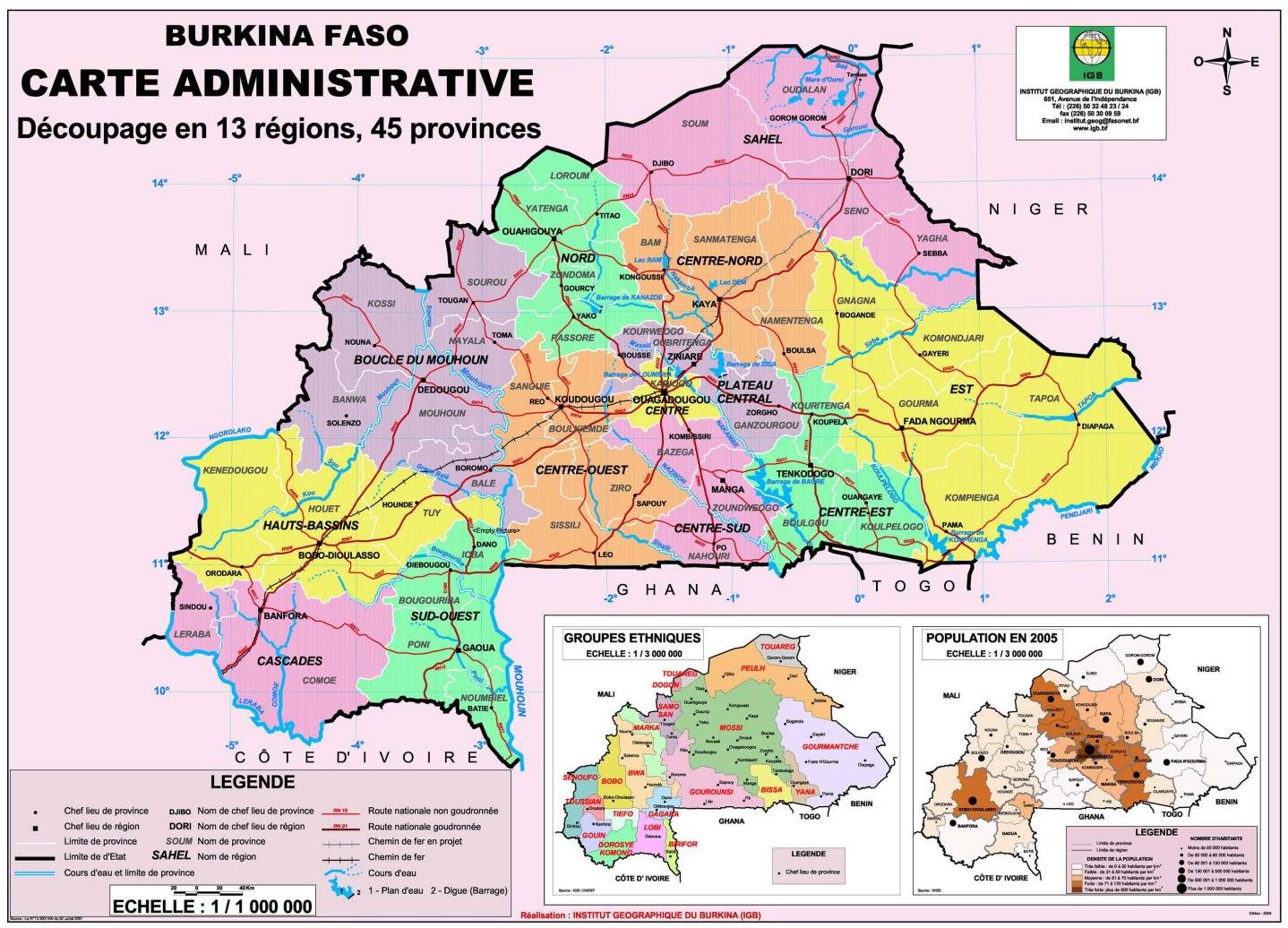

Figure 2. Administrative map of Burkina Faso (United Nations, 2014). 


\subsection{Koudougou, a City and Its Surroundings}

The town of Koudougou is about $580 \mathrm{~km}^{2}$ in size. In 2006, the town's urban population amounted to 88,184 inhabitants, to which are added 15 villages in the municipality, as indicated in the Figure 3, giving an average density of 11.91 inhabitants per hectare over an area of 7407 hectares. In 2030, the year scheduled by the master urban development plan (SDAU) (MHU, 2012), the town will reach 235,085 inhabitants, rural and urban population combined, according to an annual growth rate of $4 \%$ per annum of the municipal population. This steadily increasing population generates enormous needs to be met. Koudougou is in an area where natural resources are precarious and where the ecological balance is virtually broken.

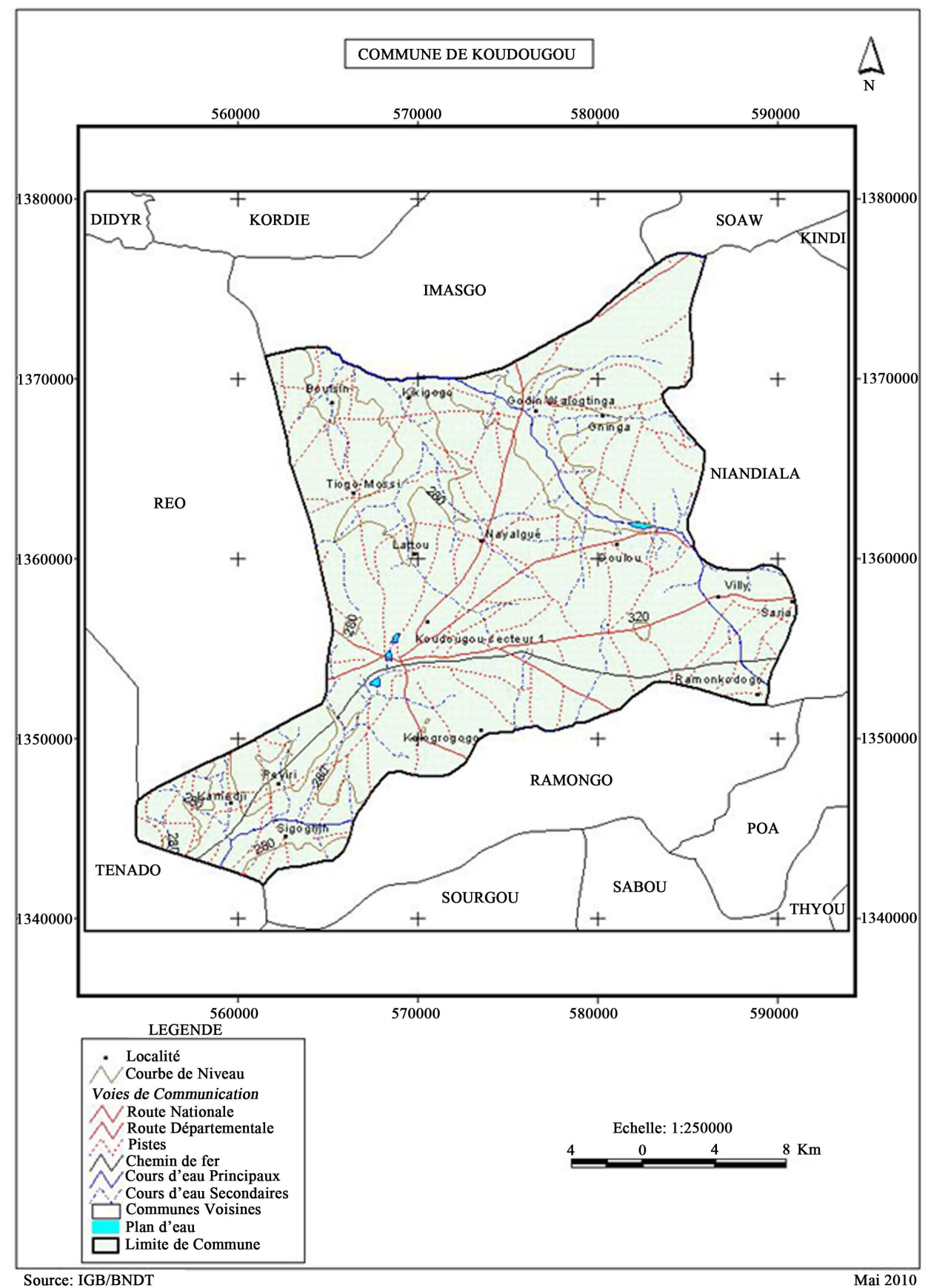

Figure 3. Municipal boundaries of the city of Koudougou (Municipality of Koudougou (2010). 
Koudougou has given rise to many studies, planning documents and prospective vision. It was first the Communal Development Plan (PCD), developed using a long participatory process from 2002 to 2005, for a period extending until 2006! The plan identified the priority needs up to a budget of more than 7 billion FCFA ${ }^{1}$ for its implementation, not commensurate with the financial capacity of the municipality of Koudougou. Because the mandate expired in 2006 and with no other third party financing, the plan was not executed. It is currently under review, with more modest ambitions in the order of one billion FCFA, more in line with the limited resources of the Koudougou Commune. The municipal Council was to have adopted it in March 2014. There was also the first master urban development plan (SDAU), covering the period 2002-2017, prepared under the authority of the General Directorate of Urban Planning in 2002, but it has never been implemented; a new version of the development plan was adopted by the Council of Ministers in December 2013. Added to this is, among the key initiatives, a strategic plan for sanitation financed by France (AFD, French Development Agency) and adopted in 2005 for a period of 10 years for the construction of 7000 latrines, of which 5000 have been realized to date. As well as a study on the management of household waste in the city of Koudougou, which led to a strategic plan in 2007 that is still pending. At the national level two decisions integrate the urban planning of Koudougou: the national planning strategy scheduled for 2025, for which the last design phase is underway; and a city contract, concluded in 2011 as part of a national program funded by the World Bank for six regional capitals "Regional Development Poles, RDP”.

Plans follow one another and multiply, at the request of national authorities, or at the suggestion of international donors. But they become obsolete, without actually being realized, since they are based on actual needs identified, but without taking into account local resources and hypothetical external contributions. This is one of the cruxes of the problem, as lived by many poor cities, without having the means to fulfill their ambitions. Or without the cities having their say in the face of national decisions, for which they are not really consulted.

The real problems lie elsewhere and remain unresolved. According to Léandre Guigma (2010) urbanization of the city of Koudougou gradually extended, first, linearly along the central highway from Ouagadougou to Dédougou, as well as on the edge of the railway, and then concentrically around a first housing estate realized in 1925. Today the town extends over a length of 10 kilometers from east to west and $9 \mathrm{~km}$ from north to south.

The city consists of an administrative area, a shopping area, an industrial area, a university area, as well as residential areas. These represent duly developed districts, mainly in the highly urbanized center, informal settlements on poorly serviced land plots with undefined pathways, as well as older villages now administratively attached to the municipality. In terms of land-use, to date, there are more than 60,000 parcels that have been made available in the municipality, for a total of nearly 7000 hectares, as shown in the Figure 4 . This is huge for a population of nearly 113,000 inhabitants, and will represent one of the major problems regarding the regularization of land and the development of plots. But this is explained by political and marketing reasons. Depending on the period, mayors sell parcels of communal land to fill the coffers of the city, and enrich themselves along the way. This is done outside of any reference to the different bodies of planning and development that have marked recent history.

\subsection{Implementation, Between Texts, Men and Resources}

In practice, how does this translate? How do these structures, these organizations, and these texts become specific practices, specific actions, knowing that each time we are speaking not of an abstraction but of a medium-sized urban cluster, according to common demographic criteria, although representing, for Koudougou, one of the five to ten cities that actually constitute the urban fabric that animates the country.

Koudougou has, as have Fada N'Gourma and Ouahigouya, other cities of Burkina Faso, benefited from the development program of medium-sized cities funded by the Swiss Cooperation and which, in addition to investments in merchant community facilities (in Koudougou, 2 fresh food markets, a bus station soon to be inaugurated and a future slaughterhouse).

Additional benefit since 1997 has come from a specific organization set up for the design, implementation and monitoring of these achievements, under the supervision of the municipal authorities. The EPCD (Bolay, 2007), a communal public development institution, was first an implementation structure of the program and then positioned itself as the project manager, delegated by the City Council to carry out, on behalf of the municipality, all of the infrastructure and activities jointly assigned to promote the development of the city. The specificity of

${ }^{1}$ At the rate of 1 euro $=655$ FCFA, this represents a total of 10,671,431 euros. 


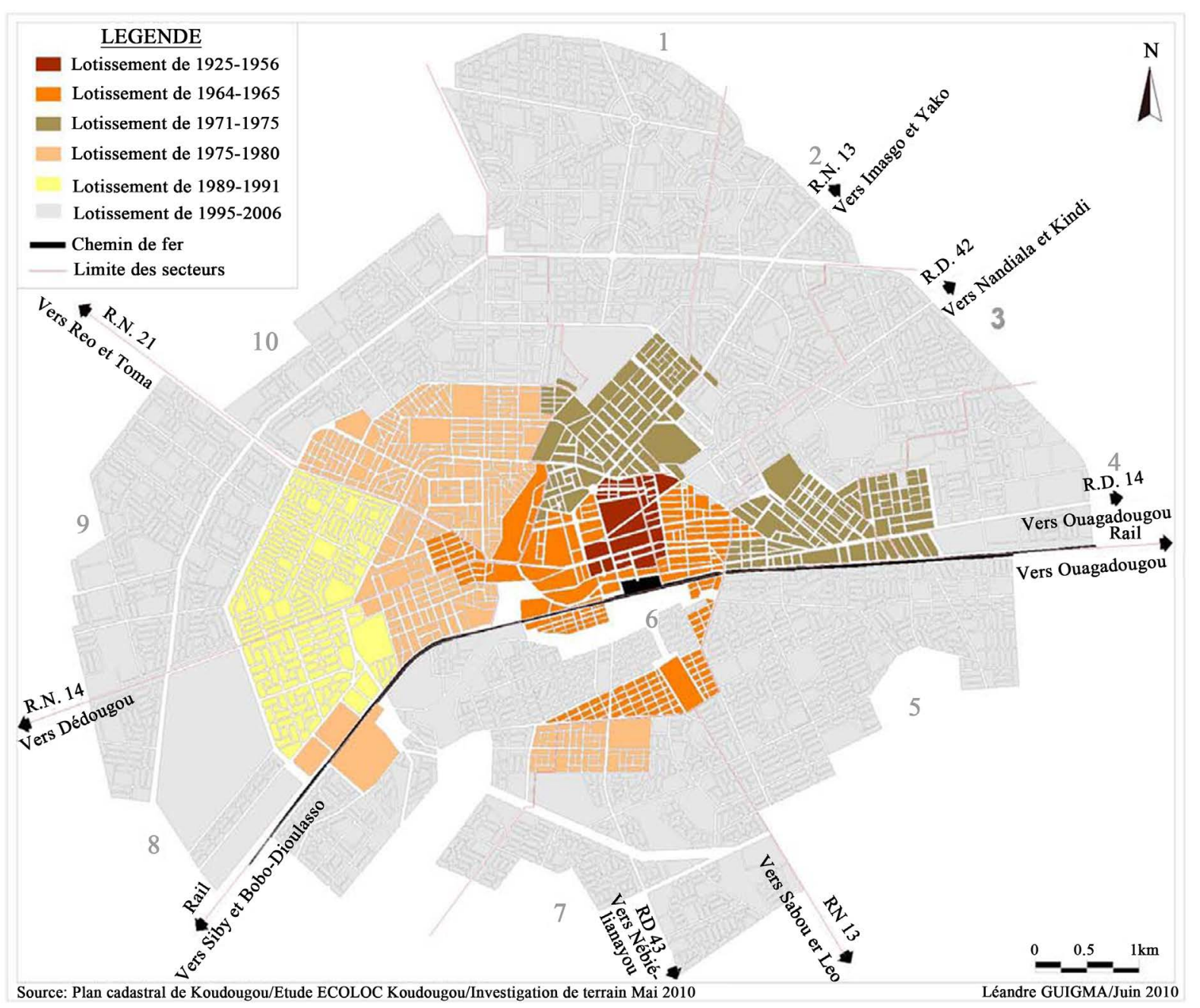

Figure 4. Central urban district of Koudougou (Municipality of Koudougou, 2010).

Koudougou is that the Director of EPCD is also the director of the technical department of the city, which, in turn, comprises three sectors: construction, roads, water and sanitation. A technician represents each sector, with no other permanent staff. To overcome the lack of skilled staff, the City Council appealed to the Ministries to provide some specialized officials ${ }^{2}$. Also involved in the municipality, regional and provincial representatives in fields as diverse as the economy, agriculture and water resources, land, infrastructure, education, social welfare, sports and recreation, and health; as well as three public companies in charge of water and sanitation, electricity and telecommunications.

The fact remains that the Commune is in the context of decentralization, responsible for the maintenance of school centers, health centers, cultural and sports facilities, commercial facilities, bus stations and parking areas, streets, rain water drains, green areas, boreholes and wells.

In 2014 the annual budget of the town of Koudougou amounted to 450 million CFA francs (FCFA), or 686,350 euros $^{3}$. Of this amount, the Mayor estimated that $85 \%$ of the total was to be devoted to operating costs (salaries and other current expenses). The actual funding capacity is currently around 70 to 80 million FCFA ${ }^{4}$ per year. Decentralized management of the two markets for fresh food, under the control of the EPCD, allowed, depending on the year, to harvest an additional 35 to 40 million FCFA, which are in turn reinvested in new

\footnotetext{
${ }^{2}$ Currently the city administration has a Treasury inspector, an educational consultant and a specialist in communication. The City Hall has extended its search to: a planner, a land specialist, a quaestor and a human resources director.

${ }^{3}$ One euro $=655$ FCFA (March 2014).

${ }^{4}$ Between 106.750 and 122.000 euros.
} 
equipment ${ }^{5}$. By adding funding from central government for infrastructure and equipment located on the territory of the commune, the entire public budget would reach one billion CFA francs, or nearly 1.5 million euros in 2014.

From the outset, initial information shed light on three aspects of urban planning on which we will focus in more detail when we look at the remarks of persons interviewed and documents consulted: the public budget is very weak in view of the needs identified by the authorities and by the population of Koudougou; very few persons are employed by the Koudougou Commune; the competency level of the majority of people involved is relatively low, politically as well as in terms of administration and technology, and third parties are often called upon.

To synthesize these three observations, one can thus say that at first glance, the city of Koudougou has insufficient financial and human resources to treat its territorial problems independently. The city is absolutely obliged to rely on external partners in a relationship that, although perhaps not directly and brutally dependent, is nevertheless part of a process of continuous negotiations in which the Commune of Koudougou is in a weak position.

When we push the analysis further, it appears that all written and oral discourse around planning in Koudougou is primarily technical and pragmatic. Without claiming it to be deceptive objectivity, there is little reference made to concepts specific to the fields of urban science, or other fields of thought. Certainly there are general texts that rely on the concepts used internationally. Thus, in its 2008 national housing and urban development policy, the Ministry of Housing and Urban Development puts forward the need to "find a comprehensive strategy to address urban issues in order to bring together the conditions for the emergence of sustainable urban development". It emphasizes a holistic understanding of urban reality and makes a step towards "strategic planning”. In 2005 Bayili and Aweh (2005) edify, at the request of UN-HABITAT, the national report of the profile of the urban area of Burkina Faso, with the aim, according to the authors, "to contribute to the development of policies to reduce urban poverty at local, national and regional levels in the African regions and the Arab States, through an assessment of needs and response mechanisms, as a contribution to the implementation of the Millennium Development Goals (MDGs)". In 2011, Alain Bagré reiterated, "cities are not built by urban planners, but by people. The new vision of urban management should reflect cities of the majority and structure its efforts to support the dynamism, creativity, democracy, and sustainability that are found within the urban majority. A strategy is needed to persuade professionals (urban planners, administrators, engineers, etc.) that it is in their interest to remove the old urban management principles, those that benefit particularly the powerful minority, to move towards a new approach".

These references are cited to emphasize both their importance-field actions are not produced from a blank slate!-But also their chronic absence from most of the reports produced for Koudougou. These concepts disappear almost exclusively to the benefit of technical and descriptive diagnosis. But they generally take no distance and do not allow for a broader or even more critical reflection, faced with the immediate objectives assigned to documents produced, whether official texts prepared by the authorities, or orders to any consultant working for a public, national or local client, most often financed by a third party, an international organization, either of the World Bank or bilateral cooperation agency type, or a Swiss or French cooperation agency.

A second observation is that few urban researchers include work on Burkina Faso ${ }^{6}$, and even less on Koudougou. Where such studies exist, the main place of interest in the country is undoubtedly the city of Ouagadougou (Biehler, 2006; Fourchard, 2001; van Dijk, 1986). At the sectoral level, the vast majority of articles available on the Internet that relate to urban Burkina Faso cover health and medical issues, and are therefore a bit on the margins of our urban planning issues.

Nevertheless, a number of these works can be cited (without claiming to be exhaustive) as emblematic of the focus of scientists in regard to the cities of Burkina Faso. This comparative approach (Obrist, 2013) does not focus exclusively on the intentions and actions generated by public institutions and the experts they appoint. For Söderström, Dupuis and Leu (2013), referring to the urban Ouagadougou, forms of urbanization repeat from one African city to another. The same experts, the same sources of financing for the same products, for which the results should be questioned. This is also what Chenal puts into question in his work on the planning of the urban space in West Africa (2013): Plans exist, produced by national and/or foreign experts, but are rarely followed

${ }^{5}$ Following the social unrest that shook the city of Koudougou in 2011, traders stopped paying rent for their shops and stalls. And taxes decreased to some 5 million FCFA. But as calm was restored, it is expected that finances will improve.

${ }^{6}$ This does not mean that there are not any, but few are referenced and easily discernible from Internet search tools. 
up as such, the financial means, even with the support of international donors, not allowing it. But they serve sometimes to promote more specific actions. The only author to have worked on Koudougou, Hilgers (2009) shows how this city, rebellious against the power in place, has developed a common urban identity creating a sense of belonging, producing a comprehensive view of the city, made of urbanity, of collective affinity and of recognition among city dwellers, but also of a rebellious city. But the author does not go any further than other researchers cited earlier in everyday urbanity that constitutes the substratum of its future development, land management and of its inhabitants today and in planning tomorrow.

Given this scientific literature to which no planner refers, official texts are intended as operational. Thus the Master Urban Development Plan of the city of Koudougou, adopted at government level in December 2013, recalls that faced with a demographic growth rate of $4 \%$ for the coming years, the needs to be satisfied are enormous and the ecological balance is almost broken, representing a major constraint for a balanced development of the territory and its population.

These bibliographic references, in counterpoint, each against the other, in turn deserve to be compared with what one learns from the land (a total of 16 people $^{7}$ interviewed at length about their vision of the city and its present and future development).

A key word used by several interlocutors is that of "vision". One must have a vision, project oneself into the future of the city and its inhabitants to then envisage planning for land development. Although rarely specified, this view should be optimistic. The mayor, in office only recently, is part of this movement, driven by an ideal that showcases the potential of the city of Koudougou-its youth, its dynamic economic participants, its geographical proximity, and its easy connection with the capital. Another theme broached, that of “development”. The city has a development potential. But it should aim to be based on the needs and abilities of people, and rely on the local economy. It cannot, however, be exclusively endogenous; city resources do not allow it, neither financially nor in human terms. It implies cooperation with the State first, then with international donors, as well as with other cities in the framework of decentralized cooperation projects. In the case of Koudougou, and by extension in Burkina Faso in certain ways, the political dimension of urban development is a major concern of all interlocutors, whether they are the outcome, the constituents, or the partners. There is a lack of confidence within the population towards the political world: “people have the impression that we don't take care of them”. The second criticism is the non-completion of the decentralization process of political power, which suffers from centralism, in which the state acquires a large number of decision levers at the expense of regions and municipalities. Which puts them into very marked dependencies, financially but also ideologically. Koudougou, according to those parties involved, is a city unloved by the central power. This high politicization of debates on the future of the city makes urban planning difficult and random, since the needs of the city are enormous, the means are insufficient, and the people are wary of politicians who prefer "major works" to an organization that is more coherent over time for the municipal territory. Good governance should, according to the personalities encountered, be the result of a political will to anticipate problems and strategies to meet them.

\subsection{What Sense to Urban Planning in Koudougou}

There have been many, even very many, plans drawn up for the city of Koudougou over the past fifteen yearssome with an overview as are the local development plans or master plans — or more sectoral as the strategic sanitation plan or strategic household waste plan. Their advantage is that they give a picture of the investments to be made to improve the situation in the municipality. Their great weakness is that they are not executed because they are out of step with the financial means and the competencies of the municipal administration. At best, they serve to reassure donors during financial negotiations. We face this fundamental contradiction as we face the objectives of urban planning.

What do the stakeholders say? What are the intentions of this urban planning that has largely developed in Burkina Faso since the 2000s, in line with the strategies of international organizations that support the government in its development efforts?

The plans do not meet the traditional goals to develop the future of Koudougou, but mark the ambitions of the authorities facing the organization of the territory. And it is clear that challenged by the multitude of problems to solve, it is difficult, both politically and technically, to set priorities in terms of areas and sectors. Everything immediately becomes a priority, without criteria that justifies choices made. And consultation frameworks

\footnotetext{
${ }^{7} 9$ are involved in management studies for Koudougou, 6 are urban specialists of Burkina Faso and one person is an NGO member.
} 
between policy makers, operators and population—if they are desired and recognized useful—are gradually set aside, for lack of resources and available time. In fact, much focus is put on the tool, implementing a proven technicality (that of consulting firms mandated to do this), and on the indicative outcomes-and very little on the approach and the objectives of the application of this instrumentation.

The second very large problem encountered is related to the conditions of the production of urban development plans, in Koudougou as in other cities of Burkina Faso. Three stumbling blocks: the first is that these local plans are decided by the national government and "imposed" on the municipalities; the second comes from the fact that the municipal administration of Koudougou, like many Burkinabe cities, is under endowed with competent personnel, and is thus unable to participate in the design, the supervision and the monitoring of this production of local plans. Neither does the glaring lack of financial resources allow the Municipality to implement this planning that takes more than wishful thinking and is primarily used for advocacy with funders, rather than as a guide in an assured control of local urban development. It is therefore the central government that decides, and the funding comes primarily from donors with whom it negotiates. In this context, two stakeholders take a back-seat position, although they will be on the frontline during an implementation of that plan-the Municipality and the residents. In reality working "on behalf of the municipality", but not from the municipality, or even in direct collaboration with it. There is, therefore, whatever the quality of this technical production, a disconnection between designers, operators, users and beneficiaries, which greatly weakens the structure.

Two other points will also disrupt the process. The first is the lack of confidence of the people of Koudougou in regard to political authorities, local and national, that will make them more hesitant to participate. The second: the slowness of procedures. In early 2000, the planning organization of the city of Koudougou, through a participatory process, extended over more than 5 years (Ministère de l'Habitat et de l'Urbanisme, 2011)! The approval by the national government slowed it even further. And it was necessary to restart the entire process in 2010 for this to result in endorsement by the State in early 2014. This creates a dichotomy between the central planning and the action of communal authorities.

And the conclusion of all the experts agree that planning tools exist but are not used as such, and prove to date to be unnecessary. Indeed, it is revealed by the study, they are diverted from their original purpose and become an object for urban marketing and communication with donors, since all donors think it essential that each city where they intervene includes planning. In the words of one amused speaker: the plan is a catalog of all that must be done in the municipality, donors choose what they want to finance!

No one among the people met, disputes the usefulness of planning as such, but they are all skeptical about its impact, "as it is not used, we cannot possibly evaluate it". Two rationales conflict with the overall interests of coherent and sustainable urban planning: first, the aspirations of foreign donors, to which national and local authorities will submit, are a priority and guide investments; second, the will of national and local political leaders is to make their mark on the territory by occasional symbolic "gestures" of their presence in power, rather than stewardship over the long term.

\subsection{From Marketing to Local Urban Action}

Beyond this confusion of genres, the words of local interlocutors highlight a few areas that could outline the way forward.

It emerges from conversations that Koudougou has a strong potential for regional and national development, regional as it is the center of a strong agricultural region and is the commercial hub of the department, national as its geographic proximity and excellent road network that connects it to Ouagadougou, over 100 kilometers, strengthens its attractiveness as a secondary place for tourism, congresses and events (atypical nights that are held annually at year end are the living proof).

The central and complex issue that needs to be addressed relates to the regularization of the land area. Numerous subdivisions of allotments took place in recent decades, often in a clientelist strategy by certain political leaders, and a very modest share of the land was enhanced. Property tax is extremely low and brings little to the Commune. And the current situation, potentially conflicting and strongly politicized, requires a total revisal and drastic measures. This is to avoid continuation of the current impasse in the allocation of land for the benefit of public facilities in regard to social housing for the poor who are forced to spatially extend the limits of the city, in an informal way by precarious housing in new areas where there is a shortage of infrastructure and basic networks.

This then leads to two other commonly cited areas: water, by an improvement of the drinking water supply 
network and the drainage systems of waste water; the sanitation by strengthening of anything related to dirty water, human excreta and household waste need to be collected in a systematic way and then be deposited in dumps duly appointed to that effect.

Other areas are often repeated by those interviewed. Anything related to the improvement of roads (paving, maintenance, extension), but also its use (traffic congestion and public transportation modes), or speaking of the privatization of public spaces by formal or informal businesses, which monopolize the land without sufficient financial compensation to the commune. Then, also implicit in some statements is the question of housing. Once again, everything revolves around the priorities and beneficiaries to support in order to aid the evolution from informal self-constructed housing to social housing that is connected to core networks and community facilities. It is likely that the subject remains on the fringes of discussions whenever it is considered primarily as pertaining to the private sphere, and that the question of popular habitat and its vulnerability is present in all African cities and has never found a comprehensive and extensive solution.

The organization of political governance and public administration responds in part, but only in part to a finding, repeated many times, of the insufficient numbers and competence of administrative staff. To quote a remark "employees" number 134, and only $10 \%$ of them have an acceptable level of training". Strengthening of technical and administrative skills in municipal administration is regarded as a priority; many see the ongoing training of staff as a priority for improving the current situation. As stated, technical services are reduced to their bare minimum, a total of three persons in all and for all. Working conditions are minimal: very few computers, broken down machinery, no Internet access in the technical services, no Wi-Fi. And construction site equipment that has been awaiting repair for months. It is difficult to expect to do more and better without the reorganization of these services. But with what means? For the mayor and his deputies, nothing will be possible, beyond what exists, without an arduous reform of municipal taxation, by an increase in the taxes charged to merchants, by raising property taxes, by taxing real estate. All measures that would increase the financial base of the Commune and strengthen its work capacity, including increased remuneration to municipal staff to attract and retain the necessary competencies, but that would likely displease many of the recipients of the laxity that has prevailed for many years.

The social conditions that foster such changes are based on the dynamism of a population very attached to its city and its development. Many groups exist and are active in the creation of economic activities, the promotion of their products, and in the defense of community interests, public works such as sanitation and the cleanliness of public spaces, and raising awareness of the population on social, economic and family issues.

This mobilization of the population, endogenously or at the instigation of the authorities, is certainly at the root of this "miracle" that makes the city of Koudougou, with paltry resources, an extremely weak administration, and recent extremely grave social conflicts, able to retain, at least for the center of the city, a quality of life and urbanity for which the political authorities and the population are very proud. Having said that, most of the issues rely on the trust to be reinstated between the political councilors and the public. And local authorities should understand that a more direct link with the inhabitants of the municipality must be mended. The interlocutors on numerous occasions recalled the need for consultation frameworks in planning, aiming for more effective participation of the public, either directly or through its representative groups.

\section{Conclusions: Planning the Poor City in Africa, the Real Challenge of the XXIe Century}

Urbanization in Africa is today an irreversible trend of the transformations that shape a continent in flux, and this regardless of the African country where one looks, and whatever the city concerned. Driven by mass migration of rural populations to urban centers and by natural growth that is still very strong, sustainable urban development is a question that confronts all cities, with identical problems: organizing the planning of territory in continuous demographic and spatial expansion, and, in parallel, doing its best with limited financial and human resources. If the very large African cities, national capitals or economic and political hubs enjoy comparatively more marked attention from governments and donors, the smaller sized agglomerations remain neglected and almost invariably face a multitude of glaring necessities, with no real means to respond to social demands for investing in infrastructure and community facilities that match the identified needs. These questions remain unanswered, addressed mainly in an emergency or according to the allocations provided sporadically by national governments or by foreign financiers. 
This urban context of great insecurity and uncertainty about the future allows us to speak of "poor cities", not only because the majority of their citizens actually live on the edge of destitution, but also because urban authorities are poorly equipped in means to assume the investment that would be needed to improve the daily life of all residents.

In this context specific to African cities, urban planning must be completely rethought and taken out of the patterns of development models that were designed for completely different environments, being for the most part the simple reproduction of defined standards and rules implemented in Western countries by specialists whose credentials are totally foreign to African countries. The major risk in this situation is that of projecting the African city on a basis that will serve only the interests of a minority of citizens, favoring the most advantaged in economic and territorial development, and leaving the modest population on the margins, those living in informality and in the most underserved neighborhoods. But it also represents an extraordinary opportunity to think about the future from what exists, taking into account the real resources, not only financial but also social, to devise and implement urban planning with the goal to fight against poverty and invest in equipment that has a sustainable impact on the living conditions of the poor.

As such, the analysis carried out in Koudougou, Burkina Faso, is very instructive. Provincial capital 100 kilometers from Ouagadougou, Koudougou is a commercial and political center of a large rural area, but it has also long been considered as a rebellious city, unwilling to obey the requirements of the Burkinabe central government.

In Koudougou, as in many intermediate African cities, the urban planning process is exogenous, not really consistent with the requests of the people, nor with the human, material and financial resources of the city, and therefore rarely applied.

This is easily explained when we know that urban planning in its design, is initiated as part of a collaborative framework between the central government and foreign donors. The initial diagnosis is made by quality professionals but who are disconnected from local administrative and social realities. In fact it is a census of all needs to be met, but without a guidance manual! How then the facilities to be created whose costs are more than ten times that of the annual municipal budget reserves? In fact, plans produced in this context do not serve to guide local authorities in the current and future development of the urban territory. Neither are they an instrument of dialogue between the said authorities and the population. On the contrary, any consultation with the community that does not result in expected and desired deliverables will strengthen the distrust, or even defiance towards public, political, and administrative powers. At best, the plans, losing their principal essence, become promotional tools, pure marketing products, a catalogue of intentions of penniless communities at the mercy of the donors' desideratum, whether they be State or foreign cooperation agencies.

This distortion of urban planning is dangerous, since it destroys any coherence in the process, both in establishing priorities in infrastructure and equipment to realize, in the economic and social sectors to be favored, as in the implementation timeframes. Nothing more can be programmed, since all work is done depending on external funders, without continuity, without a guiding principle, and without any possible guarantee that things will be done on time, potentially creating more long term disorganization than anything else.

Urban planning in African cities must be entirely reconsidered. The essential point-too often overlooked-is to begin from a participatory diagnosis in which the actual situation of the city is examined in its various dimensions, both demographic and spatial, infrastructural, but also economic, social and environmental, permitting all the stakeholders to position themselves. This information, cartographic, as well as documentary and anthropological, will serve as the foundation for the establishment of a computerized database that can then be fed in real time, facilitating the monitoring of "urban development" and a collaborative, up-to-date decision-making process. In parallel is the question of establishing priorities, in terms of structures to be built, but also in terms of standards, rules and plans tailored to the context, with regard to the needs identified by specialists, to requests from the different social actors, as well as the available resources, both local and from external sources. Two principles should guide this work: first, that urban investments be directly or indirectly involved in the fight against poverty; second, that an overall coherence guide the specific actions in the short, medium and long term. These precepts can only be applied if the framework conditions are respected: local governments must be given the human competencies and financial resources enabling them to act. And it is not impossible if the political will is there, and is based on a legitimacy in the eyes of the population. And this inevitably involves consultation frameworks that will animate the dialogue between representatives of the population, public administration, political powers, industry professionals and other special interest groups (private sector; social, religious, and 
political groups; NGOs; etc.). Training plays a key role, as does communication and dialogue. And it is these same guidelines that should guide implementation. Here too there is room for innovation, starting with the social practices and deployed human dynamics, beyond any formalism, on the local level. While it is clear that it takes the technical know-how of experts of the city and businesses, we must also remember that the own inhabitants did not wait to take the place of these players-too often absent-to build their houses, build community facilities, to better manage their neighborhoods.

These vital forces should neither be overlooked, nor marginalized; they are the center of a participatory process that is not limited to the consultation but goes from conception to action. They must be integrated into the planning process and thus contribute concretely to the implementation of decisions taken collectively. Communication is also a key issue. How to learn from other cities via the Internet and increasingly frequent global exchanges on urban matters. Whether we look at the frequent international summits on these issues by the United Nations or at visits of municipal delegation between continents. If, as indicated by Campbell (2012), we learn from near and far, and learning is no longer unilateral from North to South, but also from South to South and South to North. There nevertheless remain three reservations in this regard: first, urban technological innovations, even from emerging countries, are first found in the largest and richest agglomerations; in return, small and medium sized cities remain on the margins of these innovative processes and rarely have the opportunity to apply them, for lack of means; the question of precarious housing and urban poverty is generally treated as a problem, without utilizing and applying in similar contexts the lessons learned from this situation; and to complete these remarks, it is clear that African cities are rarely cited as examples in their approaches and treatment of urban issues.

These views are not so arrogant as to believe that all problems will now magically be solved, but rather that we are breaking out of a vicious circle in which urban planning is not playing its role, totally disconnected from a complex and changing reality. And put forward, as an innovative alternative, a more realistic vision, more pragmatic, based on what exists and focusing the efforts of all the citizens in favor of a gradual improvement in well-being for all, giving priority to the most deprived urban citizens.

\section{References}

Agboda, B., \& Watson, V. (2013). Who Will Plan Africa's Cities? London: Africa Research Institute. http://www.africaresearchinstitute.org/publications/counterpoints/who-will-plan-africas-cities/

Ascher, F. (2000). Ces événements nous dépassent, feignons d'en être les organisateurs; essai sur la société contemporaine. Paris: L'aube.

Bayat, A. (2004). Globalization and the Politics of the Informals in the Global South. In A. Roy, \& N. Alsayad (Eds.), Urban Informality. Transnational perspectives from the Middle East, Latin America and South Asia (pp. 79-102). Lanham, Boulder, New York, Toronto, Oxford: Lexington Books.

Bayili, P., \& Aweh, M. (2005). Profil du secteur urbain du Burkina Faso, rapport national, contribution aux politiques de réduction de la pauvreté urbaine en Afrique et dans les pays arabes. Nairobi, Dakar: UN-HABITAT \& IAGU.

Benjamin, N., \& Mbaye, A. A. (2012). Les entrerprises informelles de l'Afrique de l'Ouest francophone. Paris, New York: Agence Française de Développement, World Bank.

Biehler, A. (2006). Renouveau urbain et marginalisation. Le cas d'habitants du centre-ville de Ouagadougou, Burkina Faso. Revue Tiers Monde, 1, 57-78. http://dx.doi.org/10.3917/rtm.185.0057

Bolay, J.-C. (2006). Slums and Urban Development: Questions on Society and Globalization. The European Journal of Development Research, 18, 284-298. http://dx.doi.org/10.1080/09578810600709492

Bolay, J.-C. (2007). Slums Medium-Sized Cities: Poles of Regional Development in Burkina Faso. UrbanNews, 15, 2-3.

Bolay, J.-C. (2011). Une Afrique urbaine au-delà de la survie-vers une planification à la hauteur des enjeux. In $L a$ planification territoriale en Afrique, comment répondre aux enjeux? Rheinfelden, $\mathrm{CH}$ : Collage, Périodique d'urbanisme, d'aménagement et d'environnement. FSU.

Bolay, J.-C., \& Rabinovich, A. (2004). Intermediate Cities in Latin America, Risks and Opportunities of Coherent Urban Development. Cities, 21, 407-421. http://dx.doi.org/10.1016/j.cities.2004.07.007

Bolay, J.-C., Rabinovich, A., de la Porte, C. A., Ruiz, L., Unda, M., Vivero, M., Serrano, T., \& Nieves, G. (2004). Interfase urbano-rural en Ecuador. Hacia un desarrollo territoral integrado. Lausanne: Cahier du LaSUR 5, LaSUR, EPFL.

Brenner, N. (2009). What Is Critical Urban Theory? City, 13, 2-3. http://dx.doi.org/10.1080/13604810902996466

Brenner, N., \& Schmid, C. (2014). The “Urban Age” in Question. In N. Brenner (Ed.), Implosions/Explosions. Towards a Study of Planetary Urbanization (pp. 310-337). Berlin: Jovis Verlag. 
Campbell, T. (2012). Beyond Smart Cities. How Cities Network, Learn, and Innovate. London, New York: Earthscan.

Castells, M. (1969). Théorie et idéologie en sociologie urbaine. Sociologie et Sociétés, 1-2, 171-192. http://dx.doi.org/10.7202/001125ar

Chenal, J. (2013). Modèles de planification de l'espace urbain. La ville ouest-africaine. Geneva: MétisPresse.

Choay, F. (1999). De la ville à l’urbain. Urbanisme, 309, 6-8.

de Roo, G., \& Silva E. A. (Eds.) (2010). A Planner's Encounter with Complexity. Aldershot: Ashgate.

Devas, C. N., Grant, U., Mitlin, D., Rakodi, C., \& Satterthwaite, D. (2001). Urban Governance and Poverty: Lessons from a Study of 10 Cities. London: IDD, University of Birmingham/DFID.

Edensor, T., \& Jayne, M. (2012). Urban Theory beyond the West. A World of Cities. London \& New York: Routledge.

Fourchard, L. (2001). De la ville coloniale à la cour africaine: Espaces, pouvoirs et sociétés à Ouagadougou et à Bobo-Diolasso (Haute-Volta) fin XIX ${ }^{e}$ siècle-1960. Paris: L'Harmattan.

Guigma, L. (2010). Audits urbains municipaux. Commune de Koudougou. Ouagadougou, B. F.: Ministère de l'Administration Territoriale et de la Décentralisation. Direction Générale des Collectivités Territoriales.

Harrison, P. (2006). On the Edge of Reason: Planning and Urban Future in Africa. Urban Studies, 43, 319-335. http://dx.doi.org/10.1080/00420980500418368

Harrison, P., Todes, A., \& Watson, V. (2008). Planning and Transformation. Learning from the Post-Apartheid Experience. London, New York: Routledge.

Harvey, D. (2012). Rebel Cities. From the Right to the City to the Urban Revolution. London \& New York: Verso.

Hilgers, M. (2005). Du quartier au secteur, l'évolution des limites urbaines au Burkina Faso. Espaces et sociétés, 122, 67-85. http://dx.doi.org/10.3917/esp.122.0067

Hilgers, M. (2009). Une ethnographie à l'échelle de la ville: Urbanité, histoire et reconnaissance à Koudougou (Burkina Faso). Paris: Karthala.

International Labour Organization (ILO) (2014). Facilitating Transitions from the Informal to the Formal Economy. International Labour Conference (ILC). 103rd Session, Geneva: ILO.

Jaffe, E. (2011). Improving Urban Planning in Africa. An Interview with Nancy Odentaal, Project Coordinator of African Planning Schools. Citylab, 22 November 2011. http://www.citylab.com/design/2011/11/improving-urban-planning-africa/549/

Judd, D. R. (2011). Theorizing the City. In D. R. Judd, \& D. Simpson (Eds.), The City Revisited (pp. 3-20). Minneapolis, MN: University of Minneapolis Press. http://dx.doi.org/10.5749/minnesota/9780816665754.003.0001

Kessides, C. (2006). The Urban Transition in Sub-Saharan Africa. Implication for Economic Growth and Poverty Reduction. Washington DC: Cities Alliance \& World Bank.

Knox, P. L., \& Mayer, H. (2009). Small Town Sustainability. Economic, Social, and Environmental Innovation. Basel, Boston, Berlin: Birkhaüser. http://dx.doi.org/10.1515/9783034608978

Lefebvre, H. (1970). La révolution urbaine. Paris: Gallimard.

Ministère de l'Habitat et de l'Urbanisme (2011). Termes de références des schémas directeurs d'aménagement et d'urbanisme. Koudougou. 2 volumes. Ouagadougou: MHU.

Ministère de l'Habitat et de l'Urbanisme (2012). Schéma directeur d'aménagement et d'urbanisme (SDAU) de la Ville de Koudougou (Horizon 2030). Ouagadougou: MHU.

Montgomery, M. R., Stren, R., Cohen, B., \& Reed, H. E. (2004). Cities Transformed. Demographic Change and Its Implications in the Developing World. London: Earthscan.

Municipality of Koudougou (2010). Municipal Urban Audits. Koudougou: Municipality of Koudougou.

Myers, G. (2011). African Cities. Alternative Visions or Urban Theory and Practice. London: Zed Books.

Nunes Silva, C. (2015). Urban Planning in Sub-Saharan Africa. Colonial and Post-Colonial Planning Cultures. London, New York: Routledge.

Obrist, B., Arlt, V., \& Macamo, E. (2013). Living the City in Africa: Processes of Intervention and Intervention. Münster: LIT Verlag.

OECD (2006). Territorial Reviews: Competitive Cities in the Global Economy. Paris: OECD.

Paquot, T., Lussault, M., \& Body-Gendrot, S. (2000). La ville et l'urbain, l'état des savoirs. Paris: La Découverte. 
Roy, A. (2004). Transnational Trespassings. The Geopolitics of Urban Informality. In A. Roy, \& N. Alsayad (Eds.), Urban Informality. Transnational Perspectives from the Middle East, Latin America and South Asia (pp. 289-317). Lanham, Boulder, New York, Toronto, Oxford: Lexington Books.

Roy, A. (2005). Urban Informality: Toward an Epistemology of Planning. Journal of the American Planning Association, 71, 147-158. http://dx.doi.org/10.1080/01944360508976689

Scott, A. J., \& Storper, M. (2015). The Nature of Cities: The Scope and Limits of Urban Theory. International Journal of Urban and Regional Research, 39, 1-15. http://dx.doi.org/10.1111/1468-2427.12134

Söderström, O., Dupuis, B., \& Leu, P. (2013). Translocal Urbanism: How Ouagadougou Strategically Decentralized Cooperation. In B. Obrist, V. Arlt, \& E. Macamo (Eds.), Living the City in Africa: Processes of Intervention and Intervention (pp. 99-117). Münster: LIT Verlag.

Tacoli, C., McGranahan, G., \& Satterthwaite, D. (2015). Urbanisation, Rural-Urban Migration and Urban Poverty. London: IIED.

Tannerfeldt, G., \& Ljung, P. (2006). More Urban Less Poor. An Introduction to Urban Development and Management. London: Sida \& Earthscan.

Tranberg Hansen, K., \& Vaa, M. (2004). Reconsidering Informality: Perspective from Urban Africa. Uppsala: Nordiska Afrikainstitutet.

UN-Habitat (United Nations Human Settlements Programme) (2007). Profil urbain national du Burkina Faso $2004-2005$. Nairobi: UN-Habitat.

UN-Habitat (United Nations Human Settlements Programme) (2008). State of the World's Cities 2010/2011—Cites for All: Bridging the Urban Divide. Nairobi: UN-Habitat.

UN-Habitat (United Nations Human Settlements Programme) (2014). The State of African Cities. Re-Imagining Sustainable Urban Transitions. London: Earthscan.

United Nations (2014). United Nations Programs on Global Geospatial Information Management. New York: United Nations.

http://unstats.un.org/unsd/geoinfo/ungegn/docs/10th-uncsgn-docs/Exhibition\%20posters/Burkina\%20Faso\%20Map.jpg

Van Dijk, M. P. (1986). Burkina Faso. Le secteur informel de Ouagadougou. Paris: L’Harmattan.

Watson, V. (2009). Seeing from the South: Refocusing Urban Planning on the Globe's Central Issues. Urban Studies, 46, 2259-2275. http://dx.doi.org/10.1177/0042098009342598

Woltjer, J. (2000). Consensus Planning: The Relevance of Communicative Planning Theory in Dutch Infrastructure Development. Aldershot: Ashgate.

World Bank (2002). Upgrading of Low Income Settlements. Country Assessment Report. Burkina Faso. Washington DC: World Bank.

Wyly, E. (2012). Theories of Urban System Development. Introduction to Urban Geography. Vancouver: University of British Columbia.

Yftachel, O. (2006) Ethnocracy, Land and Identity Politics in Israel/Palestine. Philadelphia, PA: University of Pennsylvania Press. 